\title{
Toward a realistic density functional theory potential energy surface for the $\mathrm{H}_{5}^{+}$cluster
}

\author{
Patricia Barragán, ${ }^{1}$ Rita Prosmiti, ${ }^{1, a)}$ Octavio Roncero, ${ }^{1}$ Alfredo Aguado, ${ }^{2}$ Pablo Villarreal, ${ }^{1}$ \\ and Gerardo Delgado-Barrio ${ }^{1}$ \\ ${ }^{1}$ Instituto de Física Fundamental, CSIC, Serrano 123, 28006 Madrid, Spain \\ ${ }^{2}$ Departamento de Química Física, Facultad de Ciencias C-XIV, Universidad Autónoma de Madrid, \\ 28049 Madrid, Spain
}

(Received 8 April 2010; accepted 29 June 2010; published online 2 August 2010)

\begin{abstract}
The potential energy surface of $\mathrm{H}_{5}^{+}$is characterized using density functional theory. The hypersurface is evaluated at selected configurations employing different functionals, and compared with results obtained from ab initio $\operatorname{CCSD}(\mathrm{T})$ calculations. The lowest ten stationary points (minima and saddle-points) on the surface are located, and the features of the short-, intermediate-, and long-range intermolecular interactions are also investigated. A detailed analysis of the surface's topology, and comparisons with extensive $\operatorname{CCSD}(\mathrm{T})$ results, as well as a recent ab initio analytical surface, shows that density functional theory calculations using the $\mathrm{B} 3(\mathrm{H})$ functional represent very well all aspects studied on the $\mathrm{H}_{5}^{+}$potential. These include the tiny energy difference between the minimum at $1-\mathrm{C}_{2 v}$ configuration and the $2-\mathrm{D}_{2 d}$ one corresponding to the transition state for the proton transfer between the two equivalent $\mathrm{C}_{2 v}$ minima, and also the correct asymptotic behavior of the long-range interactions. The calculated binding energy and dissociation enthalpies compare very well with previous benchmark coupled-cluster $a b$ initio data, and with experimental data available. Based on these results the use of such approach to perform first-principles molecular dynamics simulations could provide reliable information regarding the dynamics of protonated hydrogen clusters. (C) 2010 American Institute of Physics. [doi:10.1063/1.3466763]
\end{abstract}

\section{INTRODUCTION}

The protonated hydrogen clusters, $\mathrm{H}_{3}^{+}\left(\mathrm{H}_{2}\right)_{n}$, along with their fundamental interest as benchmark systems are also of considerable present day relevance for modeling planetary atmospheres and interstellar clouds, ${ }^{1-3}$ for nuclear fusion reactions ${ }^{4,5}$ and energetic Coulomb explosions, ${ }^{6}$ as well as for a possible medium for energy storage. ${ }^{7,8}$ The first and most stable member of the cluster series, the $\mathrm{H}_{5}^{+}$, has been the subject of a numerous theoretical ${ }^{9-27}$ and experimental ${ }^{28-34,36}$ studies. All theoretical high-level ab initio studies predict the asymmetric $\mathrm{C}_{2 v}$ structure as the global minimum on the $\mathrm{H}_{5}^{+}$surface, while recent Monte Carlo calculations have shown that the zero-point averaged structure corresponds to the symmetric $\mathrm{D}_{2 d}$ geometry, ${ }^{27}$ with the proton in the middle of the two $\mathrm{H}_{2}$ diatoms. However, apart from theoretical predictions on its structure and energetics, the present experimentally confirmed knowledge of the ion is still rather limited. The available molecular spectra, ${ }^{32,34}$ which consist of broad rotationally unresolved bands, only provide few vibrational frequencies of $\mathrm{H}_{2}$ and $\mathrm{H}_{3}^{+}$stretching modes, while various experimental ${ }^{28-31,37-39}$ data are available for dissociation enthalpies and entropies for the $\mathrm{H}_{3}^{+}$ $+\mathrm{H}_{2} \rightarrow \mathrm{H}_{5}^{+}$clustering reaction. More recently, new experimental infrared photodissociation spectra have also reported. ${ }^{35}$ From these spectra vibrational frequencies associated with the shared-proton stretch mode have been assigned, and upper limits for the dissociation energies $\left(D_{0}\right)$ for

${ }^{a)}$ Electronic mail: rita@imaff.cfmac.csic.es. the $\mathrm{H}_{5}^{+}$and $\mathrm{D}_{5}^{+}$ions have been also established. ${ }^{35}$ In addition, several experimental studies of $\mathrm{H}_{3}^{+}+\mathrm{HD}$ reaction and its isotopic analogs have been performed. ${ }^{40-42}$ Rate coefficients even at typical interstellar cloud temperatures have been measured by Gerlich et al., ${ }^{2}$ and recently new experimental data in the temperature range of 5-50 $\mathrm{K}$ have been reported by Hugo et al. ${ }^{43}$ Comparisons of predicted and observed values support that such type of gas-phase reactions is less efficient than it had been expected, indicating that different temperature-dependent mechanisms should be concerned..$^{21,25,43,44}$ Thus, in view of experimental difficulties to establish the spectroscopic characterization of $\mathrm{H}_{5}^{+}$, and its role in the gas-phase ion-molecule reaction mechanism, more extended and laborious theoretical predictions are required in order to assist further experimental investigations.

A key point for carrying out rigorous dynamics calculations to explore gas-phase solvation, cluster fragmentation, and collision processes is an accurate description of the potential energy surfaces involved. Up to now accurate potentials have been obtained either by fitting the potential parameters to available high resolution spectroscopic data, providing in this way a local description of the PES, or by performing state-of-the-art electronic structure calculations for numerous configurations to construct a global representation of the surface. The construction of such $a b$ initio potentials for polyatomic molecular systems is a complicated and computationally demanding task, and as the number of atoms increases it becomes computationally prohibitive.

Nowadays several surface generation methods have been 
proposed; ${ }^{45-48}$ however, for systems with more than four atoms they do not appear to be competitive as the overall cost associated with fitting procedure and computing the necessary $a b$ initio data can be relatively high. In turn, for the traditional fitting methods the main difficulty in constructing a global PES for $\mathrm{H}_{5}^{+}$is the choice of a suitable analytical form to properly reproduce the complicated topology of the surface at short and intermediate ranges, as well as for the anisotropic long-range region. So far, five potential surfaces have been reported in the literature for the $\mathrm{H}_{5}^{+}$, and each of them is based on different theoretical approaches. ${ }^{11,17,19,21,23}$ All these studies are heavily reliant on ab initio work, and thus relevant to this article. The first one by Nagashima et al. ${ }^{11}$ is based on a sum of site-site interactions to describe the $\mathrm{H}_{3}^{+}-\mathrm{H}_{2}$ interaction potential at fixed configurations of the fragments, fitted to MP4 $a b$ initio data, while the surface by Kraemer et $a l .{ }^{17}$ has been based on a polynomial functional form in symmetry coordinates fitted to CASSCF/MR-CISD calculations. The next one by Prosmiti et al. ${ }^{19}$ has used a first-order diatomics-in-molecules perturbation theory approach to represent the $\mathrm{H}_{5}^{+}$surface without any parametrization to $\mathrm{H}_{5}^{+}$ab initio data. The recent ones by Moyano and Collins ${ }^{21}$ and of Xie et $a l^{23}$ are the more accurate ones. The first one has been constructed by a Shepard-type interpolation on a sparse set of $\operatorname{CCSD}(\mathrm{T})-\mathrm{MP} 2$ data points, while the second one is based on a generalized many-body expansion that has full permutation symmetry, and has been fitted to $100000 \operatorname{CCSD}(\mathrm{T})$ ab initio points using large basis set. Further, these authors, by using a switching technique, have added to the fitted PES the relevant long-range contributions $^{19,23}$ to extend it. In this way they have obtained a reasonable blended surface containing the long-range interaction. Up to date this latter one is the most accurate global surface for $\mathrm{H}_{5}^{+}$, although the long-range behavior is not adequately described, and the smoothness of the switching still needs to be refined.

Following the tradition in this field, our research should focus on searching a more appropriate functional form than in previous studies, especially for representing the surface in the energy between the intermediate and long-range interactions, and then parametrize it to $a b$ initio data available for $\mathrm{H}_{5}^{+}$, and so on. As discussed above, the most accurate surface to date ${ }^{23}$ does not properly represent the asymptotes, and so far, there is no interatomic model potential available that is able to describe globally the interactions of the $\mathrm{H}_{5}^{+}$complex. Further, we should also mention that studies of larger species of this series, $\mathrm{H}_{2 n+1}^{+}$, are more complex. The difficulty in the evaluation of their potential surfaces increases with their size, and high-level calculations are only available on their equilibrium configurations. ${ }^{20,49,50}$ The potential surfaces of all these complexes are expected to be very flat and highly anharmonic, so the task to parametrize the corresponding PESs is laborious even for the $\mathrm{H}_{5}^{+}$one. An alternative way to perform dynamics computations is to carry out direct dynamics trajectory calculations ${ }^{51}$ and/or Car-Parrinello ${ }^{52}$ approach for $a b$ initio molecular dynamics simulations that combines classical nuclear dynamics calculations with first-principles electronic structure calculations within the density functional theory (DFT) framework.
The purpose of the present study is to use DFT to calculate a surface of $\mathrm{H}_{5}^{+}$. Given the high quality ab initio data computed and the available analytical PESs makes $\mathrm{H}_{5}^{+}$especially an attractive target for comparison with the DFT calculations. Thus, here the accuracy of the DFT calculations using different functionals is investigated by analyzing the topology of the PES and compared with high-level CCSD(T) $a b$ initio data, as well as with the recent analytical potential surfaces available. ${ }^{21,23}$ To our knowledge several DFT studies on $\mathrm{H}_{2 n+1}^{+}$systems have been carried out. ${ }^{14,53-55}$ The majority of them have used GGA or hybrid functionals, such as the BLYP and B3LYP (Ref. 56) ones, while in the study by Chermette et $a l .{ }^{57}$ a new functional, namely B3(H), specially designed for hydrogen-only systems, has been developed and proposed for $\mathrm{H}_{2 n+1}^{+}$clusters. As we will demonstrate here such B3(H) DFT calculations can describe with sufficient accuracy the $\mathrm{H}_{5}^{+}$surface, including various stationary points on it, as well as at intermediate and long-range configurations, and thus such computations can serve for a global representation of the potential. Such results are of particular interest for studying gas-phase solvation effects, cluster fragmentation, and/or collision processes (in astrophysical applications) following the idea of ab initio molecular dynamics simulations.

The plan of this paper is as follows. Section II describes the computational details together with the results obtained from the various DFT calculations. We examine the accuracy of our computations by comparing with $\operatorname{CCSD}(\mathrm{T})$ data, and the most recent $a b$ initio surfaces for $\mathrm{H}_{5}^{+}$: the one by Moyano and Collins ${ }^{21}$ and the analytical potential by Xie et al. ${ }^{23}$ Comparisons with previous DFT calculations as well as with the experimental data available are also discussed therein. A summary and some conclusions constitute the closing section.

\section{COMPUTATIONAL DETAILS, RESULTS, AND DISCUSSION}

All DFT calculations are carried out using GAUSSIAN03 (Ref. 58) and some initial tests are also performed with the Car-Parrinello molecular dynamics (CPMD) package. ${ }^{59}$ First, we carried out geometry optimizations using both G03 and CPMD codes in order to investigate the performance of different basis sets/functionals or pseudopotentials/ functionals, respectively. Results on equilibrium energies and configurations from some calculations with cc-pVQZ basis set and different functionals, such as the wide used GGAs (BLYP, BPW91, and PBE) ${ }^{60}$ hybrid-GGAs (B3LYP, B3PW91, and O3LYP), ${ }^{56,61,62}$ and the especially designed for hydrogen-only systems, the $\mathrm{B} 3(\mathrm{H})$ one,${ }^{57}$ as well as combination of the GGA functionals with the Vanderbilt's ultrasoft (VDB) (Ref. 63) and von Barth-Car type (CVB) (Ref. 64) pseudopotentials, as implemented in the CPMD code, ${ }^{59}$ are listed in Table I. Test calculations for the optimized geometry were performed, with and without basis set superposition error (BSSE) correction, by increasing the convergence criterion in the optimization process up to $10^{-12}$ a.u..

However, for all functionals used, except the $\mathrm{B} 3(\mathrm{H})$ one, we found an elongated $1-\mathrm{C}_{2 v}$ configuration (with the $\mathrm{H}_{2}$ molecule attached to a substantially distorted $\mathrm{H}_{3}^{+}$unit) almost 
TABLE I. Total energies (in a.u.) and bond lengths (in angstrom) of the optimal $\mathrm{H}_{5}^{+}$structure obtained by the present DFT calculations using different functionals/basis sets and their comparisons with those from a previous DFT (Ref. 14) and recent coupled-cluster calculations (Refs. 18 and 19). $R_{1} / R_{2}$ and $P$ are the $\mathrm{H}-\mathrm{H}$ bond lengths in the $\mathrm{H}_{3}^{+}$and $\mathrm{H}_{2}$ monomers, respectively, while $D$ is the intermolecular distance between one $\mathrm{H}$ atom of $\mathrm{H}_{3}^{+}$and the center of mass of $\mathrm{H}_{2}$.

\begin{tabular}{|c|c|c|c|c|}
\hline Functional/Basis set & Energy & $R_{1} / R_{2}$ & $D$ & $P$ \\
\hline PBE/cc-pVQZ & -2.5281229 & $1.1434 / 0.7966$ & 1.0718 & 0.7966 \\
\hline BPW91/cc-pVQZ & -2.5481868 & $1.1418 / 0.7923$ & 1.0707 & 0.7923 \\
\hline BLYP/cc-pVQZ & -2.5284601 & $1.1463 / 0.7905$ & 1.0760 & 0.7905 \\
\hline B3PW91/cc-pVQZ & -2.5502831 & $1.1341 / 0.7890$ & 1.0633 & 0.7890 \\
\hline O3LYP/cc-pVQZ & -2.5469864 & $1.1336 / 0.7879$ & 1.0629 & 0.7879 \\
\hline B3LYP/cc-pVQZ & -2.5478218 & $1.1368 / 0.7864$ & 1.0667 & 0.7864 \\
\hline $\mathrm{B} 3(\mathrm{H}) / \mathrm{cc}-\mathrm{pVQZ}\left(1 \mathrm{C}_{2 v}\right)$ & -2.532656 & $0.9967 / 0.7992$ & 1.2439 & 0.7611 \\
\hline$\left(2 \mathrm{D}_{2 d}\right)$ & -2.532512 & $1.1238 / 0.7770$ & 1.0545 & 0.7770 \\
\hline $\mathrm{PBE} / \mathrm{CVB}$ & -2.525592 & $1.1423 / 0.7949$ & 1.0647 & 0.7955 \\
\hline GGA/VDB & -2.529052 & $1.1447 / 0.7973$ & 1.0734 & 0.7972 \\
\hline BLYP/VDB & -2.520255 & $1.1486 / 0.7938$ & 1.0807 & 0.7935 \\
\hline $\mathrm{GGA} / \mathrm{CVB}^{\mathrm{a}}$ & N/A & $1.13 / \cdots$ & 1.06 & 0.81 \\
\hline $\operatorname{CCSD}(\mathrm{T})-\mathrm{R} 12\left(1 \mathrm{C}_{2 v}\right)^{\mathrm{b}}$ & -2.531794 & $0.966 / 0.816$ & 1.324 & 0.765 \\
\hline$\left(2 \mathrm{D}_{2 d}\right)^{\mathrm{b}}$ & -2.531514 & $1.125 / 0.780$ & 1.054 & 0.780 \\
\hline $\operatorname{CCSD}(\mathrm{T}) / \mathrm{cc}-\mathrm{pVQZ}\left(1 \mathrm{C}_{2 v}\right)^{\mathrm{c}}$ & -2.530509 & $0.9770 / 0.8127$ & 1.2918 & 0.7662 \\
\hline$\left(2 \mathrm{D}_{2 d}\right)^{\mathrm{c}}$ & -2.530217 & $1.1250 / 0.7849$ & 1.0544 & 0.7849 \\
\hline
\end{tabular}

${ }^{\mathrm{a}}$ Reference 14.

${ }^{\mathrm{b}}$ Reference 18.

${ }^{\mathrm{c}}$ Reference 19.

indistinguishable in energy with the 2- $\mathrm{D}_{2 d}$ one (with a proton symmetrically positioned between two $\mathrm{H}_{2}$ molecules) as an optimal structure for $\mathrm{H}_{5}^{+}$cluster (see bond-length values in Table I). In order to clarify the minimum energy structure, DFT calculations employing larger basis sets, such as augcc-pVQZ and aug-cc-pV5Z, were also carried out, and lower total energies of 0.00001 and 0.00005 a.u., respectively, were obtained. In Table I we also compare the results of the present DFT calculations with the results of previous DFT ones, ${ }^{14}$ as well as with recent $\operatorname{CCSD}(\mathrm{T})$ data available. ${ }^{18,19}$

As shown in Table I the hybrid functionals yield lower energy results and shorter bond length and intermolecular distances than GGA ones, being in closer agreement to the previous $\operatorname{CCSD}(\mathrm{T})$ calculations. According to those results, as we mentioned above, the $1-C_{2 v}$ structure has the lowest energy followed by the 2- $\mathrm{D}_{2 d}$ one, where the proton is situated in the middle of the two hydrogen molecules and corresponds to the saddle-point for the proton transfer. The energy difference between these two structures has been predicted by $\operatorname{CCSD}(\mathrm{T})[\mathrm{DTQ}] / \mathrm{CBS}$ calculations to be only 0.20 $\mathrm{kcal} / \mathrm{mol}^{20}{ }^{20}$ As we can see here all DFT calculations fail to reproduce them, and only the ones employing the $\mathrm{B} 3(\mathrm{H})$ functional can distinguish between these two configurations. The B3(H) DFT calculations predict an energy difference of $0.09 \mathrm{kcal} / \mathrm{mol}$ between the $1-\mathrm{C}_{2 v}$ and $2-\mathrm{D}_{2 d}$ structures. Also by comparing the optimized geometries of the DFT computations we found that the ones obtained from the B3(H)/ccpVQZ calculations are in excellent agreement with the CC$\mathrm{R} 12$ and $\operatorname{CCSD}(\mathrm{T})$ results. ${ }^{18,20}$

In Fig. 1 we plot the minimum total energy path between these two conformers at different levels of theory, such as HF, MP2, CCSD(T) together with the results of $\mathrm{B} 3(\mathrm{H})$, B3LYP, and B3PW91 using cc-pVQZ basis set, as well as the curve obtained from the recent $\operatorname{CCSD}(\mathrm{T}) /$ aug-cc-pVTZ parametrized surface. ${ }^{23}$ The distance between the centers of mass of the two $\mathrm{H}_{2}$ molecules is fixed in their equilibrium value of the $2-\mathrm{D}_{2 d}$ configuration of $\mathrm{H}_{5}^{+}$, while the $\mathrm{X}$-axis shows the position of the central proton between them. The total energy is calculated by optimizing the $\mathrm{H}_{5}^{+}$geometry for each point of the $\mathrm{X}$-axis at the specific level of theory. The $\mathrm{HF}$ approach predicts a higher barrier of $\approx 1.5 \mathrm{kcal} / \mathrm{mol}$ than

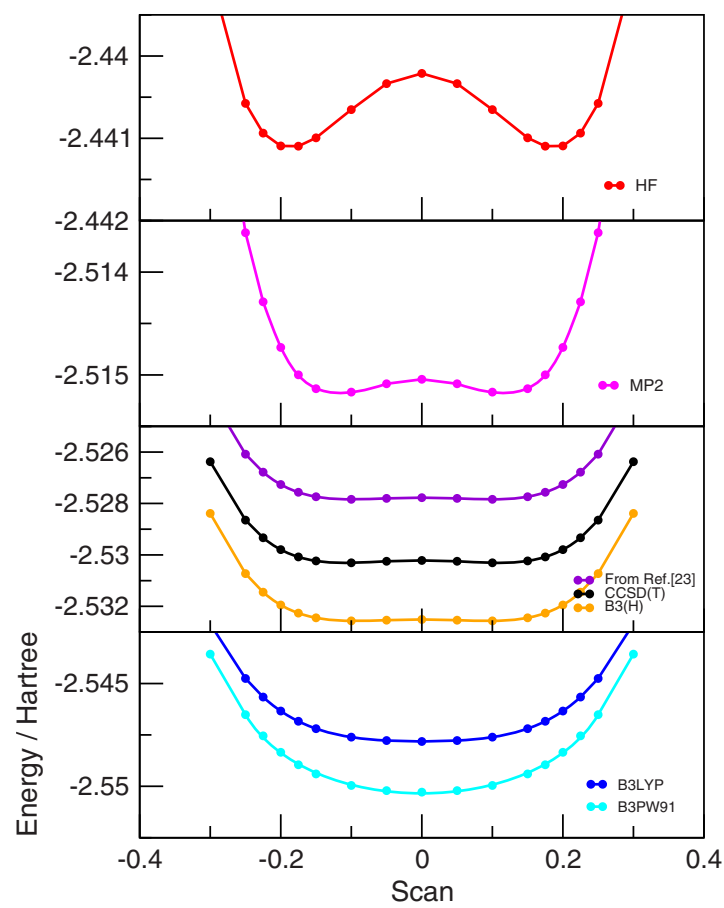

FIG. 1. Total energies for $\mathrm{H}_{5}^{+}$obtained at indicated levels using cc-pVQZ basis set, together with the ones obtained for the analytical surface from Ref. 23. The $\mathrm{X}$-axis shows the position of the central proton between the two $\mathrm{H}_{2}$ monomers, which are fixed at the $2-\mathrm{D}_{2 d}$ configuration of $\mathrm{H}_{5}^{+}$. 
TABLE II. Harmonic vibrational frequencies (in $\mathrm{cm}^{-1}$ ) for $1-\mathrm{C}_{2 v} / 2-\mathrm{D}_{2 d}$ conformers of $\mathrm{H}_{5}^{+}$calculated in the present work (DFT) and comparison with previous benchmark results. The number of the negative values indicates the order of the saddle-point.

\begin{tabular}{ccccccccc}
\hline \hline & \multicolumn{7}{c}{ This work } & \\
Mode & PBE & BLYP & BPW91 & B3LYP & B3PW91 & B3(H) & CCSD(T) & PES $^{\mathrm{b}}$ \\
\hline 1 & 227 & 223 & 226 & 228 & 230 & $204 /-449$ & $206 /-531$ & $211 /-503$ \\
2 & 870 & 674 & 841 & 534 & 705 & $607 / 234$ & $495 / 224$ & $487 / 217$ \\
3 & 895 & 890 & 900 & 922 & 927 & $796 / 965$ & $812 / 962$ & $829 / 971$ \\
4 & 895 & 890 & 900 & 922 & 927 & $890 / 965$ & $866 / 962$ & $882 / 971$ \\
5 & 1346 & 1324 & 1347 & 1363 & 1379 & $1211 / 1412$ & $1170 / 1411$ & $1190 / 1430$ \\
6 & 1464 & 1422 & 1462 & 1500 & 1529 & $1878 / 1610$ & $1838 / 1593$ & $1799 / 1616$ \\
7 & 1464 & 1422 & 1462 & 1500 & 1529 & $2165 / 1610$ & $2131 / 1593$ & $2128 / 1616$ \\
8 & 3770 & 3804 & 3797 & 3869 & 3858 & $3815 / 3989$ & $3668 / 3892$ & $3666 / 3861$ \\
9 & 3849 & 3883 & 3875 & 3951 & 3939 & $4203 / 4077$ & $4115 / 3965$ & $4091 / 3924$ \\
\hline \hline
\end{tabular}

${ }^{\mathrm{a}}$ Reference 20.

${ }^{\mathrm{b}}$ Reference 23 .

the MP2 and $\operatorname{CCSD}(\mathrm{T})$ correlated methods, where a lower barrier of $\approx 0.2 \mathrm{kcal} / \mathrm{mol}$ is obtained between the two wells. The $\mathrm{B} 3(\mathrm{H})$ functional yields a double well topology very similar to the $\operatorname{CCSD}(\mathrm{T})$ one, while all others used here, e.g., the B3LYP and B3PW91, predict a symmetric structure with a single very flat potential well. We thus conclude that the $\mathrm{B} 3(\mathrm{H})$ functional represents pretty accurately this energy path in contrast to the B3LYP and B3PW91 ones.

Further, and in order to analyze the character of the optimal structure, we carried out harmonic frequency calculations at the above mentioned stationary points of the potential surface. The results of this normal-mode analysis are given in Table II. As seen all GGAs or hybrid functional DFT calculations predict an elongated $1-\mathrm{C}_{2 v}$ structure to be the energetically lowest stationary point, and is the minimum on the $\mathrm{H}_{5}^{+}$surface with very similar normal-mode frequencies. However, among the different functionals again only the $\mathrm{B} 3(\mathrm{H})$ one predicts the existence of the $2-\mathrm{D}_{2 d}$ structure as a first-order saddle-point, with the calculated harmonic frequencies to be in very good agreement with those from previous benchmark calculations, ${ }^{20}$ as well as with the ones from the recent analytical PES. ${ }^{23}$

A more detailed and quantitative insight into the bonding may be obtained from the comparison of total and correlation energies for a specific configuration. In Table III we present such results for the optimized $\mathrm{H}_{5}^{+}$structure at $\mathrm{B} 3 \mathrm{LYP} / \mathrm{cc}-$ pVQZ level for all DFT and the CCSD(T)/cc-pVQZ calculations, and the optimized geometry at $\operatorname{CCSD}(\mathrm{T}) /$ aug-ccpVQZ one for the coupled-cluster ones. Correlation energies are computed using accordingly the exchange-correlation

TABLE III. Total and correlation energies (in a.u.) of optimized $\mathrm{H}_{5}^{+}$structures, obtained at B3LYP/cc-pVQZ and CCSD(T)/aug-cc-pVQZ levels of theory, and extrapolation of the coupled-cluster values to their CBS limit.

\begin{tabular}{|c|c|c|c|}
\hline Geometry & Method/Basis set & $E_{\text {tot }}$ & $\Delta E_{\text {cor }}$ \\
\hline \multirow[t]{6}{*}{ Optimized B3LYP/cc-pVQZ } & BPW91/cc-pVQZ & -2.5481367 & $-0.1017283^{\mathrm{a}}$ \\
\hline & BLYP/cc-pVQZ & -2.5284076 & $-0.0819992^{\mathrm{a}}$ \\
\hline & B3PW91/cc-pVQZ & -2.5502715 & $-0.1101078^{b}$ \\
\hline & B3LYP/cc-pVQZ & -2.5478218 & $-0.1077581^{\mathrm{b}}$ \\
\hline & $\mathrm{B} 3(\mathrm{H}) / \mathrm{cc}-\mathrm{pVQZ}$ & -2.5323515 & $-0.0922878^{b}$ \\
\hline & $\operatorname{CCSD}(\mathrm{T}) / \mathrm{cc}-\mathrm{pVQZ}$ & -2.5301330 & $-0.0900693^{b}$ \\
\hline \multirow[t]{9}{*}{ Optimized CCSD(T)/aug-cc-pVQZ } & $\operatorname{CCSD}(\mathrm{T}) /$ aug-cc-pVQZ & -2.5306971 & -0.0889641 \\
\hline & $\operatorname{CCSD}(\mathrm{T}) / \mathrm{AV} 5 \mathrm{Z}$ & -2.5315104 & -0.0894658 \\
\hline & $\operatorname{CCSD}(\mathrm{T}) / \mathrm{AV} 6 \mathrm{Z}$ & -2.5317353 & -0.0896532 \\
\hline & $\operatorname{CCSD}(\mathrm{T}) / \mathrm{CBS}[\mathrm{Q} 56]^{\mathrm{c}}$ & -2.5318660 & $-0.0897660^{\mathrm{d}}$ \\
\hline & $\operatorname{CCSD}(\mathrm{T}) / \operatorname{CBS}[56]^{\mathrm{e}}$ & -2.5319927 & -0.0899106 \\
\hline & $\mathrm{CCSD}(\mathrm{T}) / \mathrm{cc}-\mathrm{pV} 8 \mathrm{Z}$ & -2.5318373 & -0.0897484 \\
\hline & $\operatorname{CCSD}(\mathrm{TQ}) /$ aug-cc-pVQZ & -2.5307766 & -0.0890436 \\
\hline & $\operatorname{CCSD}(\mathrm{TQ}) / \mathrm{CBS}[56]^{\mathrm{f}}$ & -2.5320722 & -0.0899901 \\
\hline & Literature $^{\mathrm{g}}$ & -2.5320 & -0.089559 \\
\hline
\end{tabular}

\footnotetext{
$\bar{a}$ Correlation values were obtained as the difference from the HFB/cc-pVQZ energy (HF=-2.446 4084 a.u.).

${ }^{\mathrm{b}}$ Correlation values were calculated by the difference with the HF/cc-pVQZ energy (HF=-2.440 0637 a.u.). ${ }^{\mathrm{c}}$ Reference 65 .

${ }^{\mathrm{d}}$ The correlation energy was obtained by the difference of CCSD(T)/CBS[Q56] and HF/CBS[Q56] energies. ${ }^{\mathrm{e}}$ Reference 66.

${ }^{\mathrm{f}}$ These values were calculated including the contribution of quadruple excitations at CCSD(TQ)/aug-cc-pVQZ level to the $\operatorname{CCSD}(\mathrm{T}) / \mathrm{CBS}$ (Ref. 56) extrapolation value.

${ }^{\mathrm{g}}$ Reference 18.
} 
TABLE IV. Total energy (in a.u.) for the $1-\mathrm{C}_{2 v}$ global minimum structure and relative energies (in $\mathrm{kcal} / \mathrm{mol}$ ) for the indicated $\mathrm{H}_{5}^{+}$optimized conformers predicted by the present DFT calculations and compared with previous ones.

\begin{tabular}{|c|c|c|c|c|c|c|c|}
\hline \multirow[b]{2}{*}{ Conformer } & \multicolumn{3}{|c|}{ This work } & \multirow[b]{2}{*}{$\operatorname{CCSD}(\mathrm{T})-\mathrm{R} 12^{\mathrm{a}}$} & \multirow[b]{2}{*}{$\operatorname{QCISD}(\mathrm{T})^{\mathrm{b}}$} & \multirow[b]{2}{*}{$\mathrm{PES}^{\mathrm{c}}$} & \multirow[b]{2}{*}{$\mathrm{PES}^{\mathrm{d}}$} \\
\hline & B3PW91 & B3LYP & B3(H) & & & & \\
\hline $1 \mathrm{C}_{2 v}$ & -2.550283 & -2.547822 & -2.532656 & -2.531794 & -2.530509 & -2.518215 & -2.528015 \\
\hline $2 \mathrm{D}_{2 d}$ & 0.000 & 0.000 & 0.090 & 0.176 & 0.183 & 0.080 & 0.149 \\
\hline $3 C_{2 v}$ & 0.339 & 0.349 & 0.302 & 0.276 & 0.273 & 0.256 & 0.295 \\
\hline $4 \mathrm{D}_{2 h}$ & 0.339 & 0.349 & 0.483 & 0.521 & 0.520 & 0.419 & 0.458 \\
\hline $5 C_{2 v}$ & 7.377 & 8.235 & 5.075 & $\cdots$ & 4.413 & 5.635 & 4.477 \\
\hline $6 \mathrm{C}_{2 v}$ & 7.923 & 8.779 & 7.021 & $\cdots$ & 6.573 & 6.076 & 6.886 \\
\hline $7 \mathrm{C}_{2 v}$ & 7.764 & 8.650 & 5.455 & $\cdots$ & 4.781 & 5.687 & 4.795 \\
\hline $8 C_{2 v}$ & 10.769 & 11.569 & 8.384 & $\cdots$ & 7.615 & 7.139 & 7.144 \\
\hline $9 \mathrm{C}_{s}$ & 10.058 & 10.916 & 7.198 & $\cdots$ & 6.208 & 7.264 & 6.022 \\
\hline $10 \mathrm{C}_{3 v}$ & 11.792 & 12.621 & 9.105 & $\cdots$ & 8.104 & 8.011 & 7.756 \\
\hline
\end{tabular}

functionals for the GGA-type calculations, while for the hybrid functionals, as well as for the $\mathrm{CC}$ ones, their values are estimated by the difference of the corresponding HF energies. Further, extrapolation schemes to converge energies to the (approximate) complete basis set (CBS) limit are employed. In particular, we utilized one of the most widely used, the mixed Gaussian/exponential three-point form proposed by Peterson et al., ${ }^{65} E_{X}=E_{\mathrm{CBS}}+A e^{-(X-1)}+B e^{-(X-1)^{2}}$, where $X$ is the cardinal number, in the series of aug-ccpVQZ, aug-cc-pV5Z, and aug-cc-pV6Z basis sets, and the two-point single inverse power function first introduced by Schwartz ${ }^{66}$ for the correlation energies, $E_{X}=E_{\mathrm{CBS}}+A / X^{3}$, assuming the aug-cc-pV5Z and aug-cc-pV6Z basis sets. Table III also shows the results from CCSD(TQ) calculations and in current case an estimate of nearly 0.00008 a.u. (0.05 kcal/ mol) was obtained for the contribution of quadruplet substitutions with the aug-cc-pVQZ basis set to the correlation energy. Taken into account this contribution a correlation energy of about 0.08999 a.u. is predicted by the CCSD(TQ)/ CBS (Ref. 56) computations. On the other hand, from the DFT calculations somewhat higher correlation energy is estimated for the B3LYP/cc-pVQZ optimized structure, and as we can see the PW91 correlation functional overestimates the correlation energy compared to the LYP one. Further, as it was expected, the values obtained with the $\mathrm{B} 3(\mathrm{H})$ functional (0.0923 a.u) are more close to the CCSD(TQ) results (0.090 a.u) than the B3LYP one, which counts for 0.108 a.u. (see Table III). We should mention here that B3LYP functional has been parametrized for the G2 set of molecules, ${ }^{56}$ while the latter functional has been designed for hydrogenonly systems. Chermette et al. ${ }^{57}$ fitted the B3LYP functional parameters of pure exchange, gradient-corrected exchange, and gradient-corrected correlation terms to the equilibrium geometrical data of $\mathrm{H}_{5}^{+}$at $\mathrm{CCSD}(\mathrm{T})$ level of theory, whereas $\operatorname{CCSD}(\mathrm{T})$ data for $\mathrm{H}_{3}^{+}$and larger clusters up to $\mathrm{H}_{9}^{+}$have been used to evaluate the efficiency of the fit. Such parametrization has led to the B3(H) hybrid functional which includes a larger amount of pure exchange than the B3LYP one, al- though it has been found ${ }^{57}$ reasonable for hydrogen-only systems, and certainly the most important term for the longrange interactions.

In order now to further check the accuracy of the hybrid functionals we locate the ten stationary points on the $\mathrm{H}_{5}^{+}$ surface, reported by Yamaguchi et al. ${ }^{10}$ The results of the present calculations for the optimized structures are summarized in Table IV, together with the comparisons with data of previous high-level $a b$ initio calculations ${ }^{18,19}$ and the recent analytical potential surfaces. ${ }^{21,23}$ Once again the calculations based on B3(H) functional reproduce remarkably well all ten stationary points predicted by Yamaguchi et al. ${ }^{10}$ (we keep the designation introduced by these authors), and the optimal structures at the B3(H)/cc-pVQZ level for them are depicted in Fig. 2. As we can see B3PW91 and B3LYP functionals failed in reproducing the difference between the no-planar $1-\mathrm{C}_{2 v}$ and $2-\mathrm{D}_{2 d}$ conformers, as well as the planar $3-\mathrm{C}_{2 v}$ and $4-\mathrm{D}_{2 h}$ ones. Compared to the $\operatorname{CCSD}(\mathrm{T})$ data we see that small changes are predicted in geometry and in total energy of all stationary points from the B3(H) DFT calculations, although the order and energy separation of these conformers are very close to the $\operatorname{CCSD}(\mathrm{T})$ ones. ${ }^{18-21,23}$ The first four low-lying configurations (1-4) are very close to each other in energy within 0.483 a.u. for the B3(H)/cc-pVQZ compared to 0.521 a.u for the $\operatorname{CCSD}(\mathrm{T})-\mathrm{R} 12$ (Ref. 18) results, while the energy difference of the first two conformers is predicted to be $0.09 \mathrm{kcal} / \mathrm{mol}$, that is lower than the $\operatorname{CCSD}(\mathrm{T})$ one $(0.176 \mathrm{kcal} / \mathrm{mol})$, although very similar to one of the MP2 surface by Moyano and Collins. ${ }^{21}$ As it can be seen the energy separation for the configurations of the second group $(5-10)$ predicted from the $\mathrm{B} 3(\mathrm{H})$ calculations is $5.075 \mathrm{kcal} /$ mol, that is between the $\operatorname{CCSD}(\mathrm{T})$ and MP2 data, ${ }^{20,21,23}$ while the other two functionals, B3PW91 and B3LYP, predict somehow higher difference of 8.235 and $7.377 \mathrm{kcal} / \mathrm{mol}$, respectively. All functionals used predict the same relative order within these structures that is different to the one from the $\operatorname{CCSD}(\mathrm{T})$ calculations. From the B3(H) calculations a lower relative energy is obtained for the $6-\mathrm{C}_{2 v}$ compared to the $9-\mathrm{C}_{s}$ one, in agreement with the MP2 surface, ${ }^{21}$ and in 


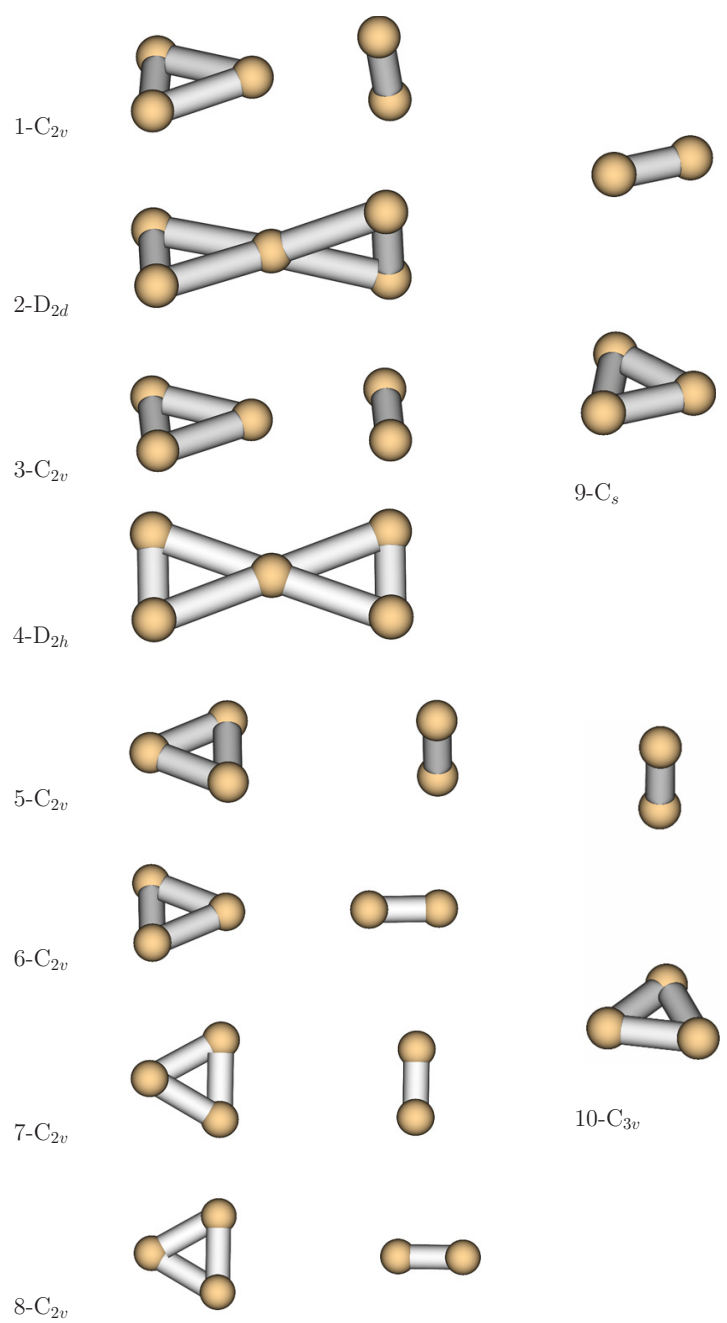

FIG. 2. Structures of the ten low-lying stationary points on $\mathrm{H}_{5}^{+}$surface obtained at B3(H)/cc-pVQZ level of theory.

contrast to the $\operatorname{CCSD}(\mathrm{T})$ estimations. However, we should note that the relative energies obtained with the $\mathrm{B} 3(\mathrm{H})$ functional for these conformers are much closer to the $\operatorname{CCSD}(\mathrm{T})$ ones than the ones estimated from the other two functionals. Based now on the Hessian analysis of the harmonic frequencies at B3(H)/cc-pVQZ level, among the ten conformers the $1-\mathrm{C}_{2 v}$ is the only minimum, while the next ones are saddlepoints of the surface of the following order: first for the $2-\mathrm{D}_{2 d}, 3-\mathrm{C}_{2 v}$, and $5-\mathrm{C}_{2 v}$, second for the $4-\mathrm{D}_{2 h}, 6-\mathrm{C}_{2 v}, 7-\mathrm{C}_{2 v}$, and $9-\mathrm{C}_{s}$, third for $8-\mathrm{C}_{2 v}$, and fourth for the $10-\mathrm{C}_{3 v}$. This is in absolute agreement with the QCISD(T) results. ${ }^{19}$

As already stated, $\mathrm{H}_{5}^{+}$cluster can be described as a distorted $\mathrm{H}_{3}^{+}$nucleus weakly linked to an $\mathrm{H}_{2}$ molecule, and a first dissociation reaction would be a lost of the $\mathrm{H}_{2}$ molecule. In order to carry out reaction or photofragmentation dynamics calculations the surface should correctly describe both the short-range, intermediate, as well as long-range features of the $\mathrm{H}_{5}^{+}$. Therefore, we performed a series of calculations at various intermolecular distances and relative orientations of $\mathrm{H}_{3}^{+}$and $\mathrm{H}_{2}$ to represent a description of the most important intermolecular interactions between the two monomers. The relative orientations of the $\mathrm{H}_{3}^{+}$and $\mathrm{H}_{2}$ are chosen according to the $1-\mathrm{C}_{2 v}, 3-\mathrm{C}_{2 v}, 5-\mathrm{C}_{2 v}, 7-\mathrm{C}_{2 v}, 9-\mathrm{C}_{s}, 6-\mathrm{C}_{2 v}, 8-\mathrm{C}_{2 v}$, and $10-\mathrm{C}_{3 v}$ low- lying structures, which are displayed in Fig. 2.

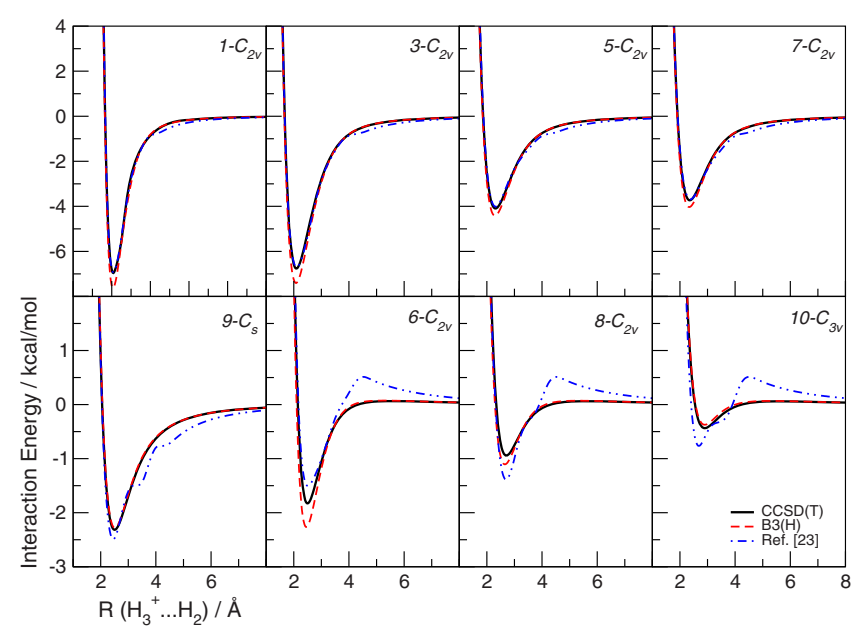

FIG. 3. Interaction energies for $\mathrm{H}_{3}^{+} \cdots \mathrm{H}_{2}$ (in $\mathrm{kcal} / \mathrm{mol}$ ) as a function of the intermolecular distance $R$ connecting the centers of mass of $\mathrm{H}_{3}^{+}$and $\mathrm{H}_{2}$ monomers in their equilibrium configurations obtained by $\operatorname{CCSD}(\mathrm{T}) / \mathrm{cc}-$ pVQZ and B3(H)/cc- pVQZ calculations, together with the values of the analytical surface from Ref. 23. The relative orientations for the two monomers (indicated in each panel) are chosen from the ten conformers of $\mathrm{H}_{5}^{+}$ (see Fig. 2).

The $\mathrm{H}_{3}^{+}$and $\mathrm{H}_{2}$ are fixed to their equilibrium geometries at $\operatorname{CCSD}(\mathrm{T})$ level, while the intermolecular distance $R$ between their center of masses is varied from 1.5 to $20 \AA$. As we show above, the $\mathrm{B} 3(\mathrm{H})$ functional provides the most reliable description of the $\mathrm{H}_{5}^{+}$potential, and thus here we only consider it to compare with the $\operatorname{CCSD}(\mathrm{T})$ data. The results of the $\mathrm{B} 3(\mathrm{H}) / \mathrm{cc}-\mathrm{pVQZ}$ and $\mathrm{CCSD}(\mathrm{T}) / \mathrm{cc}-\mathrm{pVQZ}$ calculations together with their comparison with the ones obtained from the recent analytical PES by Xie et al. ${ }^{23}$ are presented in Fig. 3. The interaction energies are relative to the $\mathrm{H}_{3}^{+}+\mathrm{H}_{2}$ dissociation limit for each level of calculation. One can see that the $\mathrm{B} 3(\mathrm{H})$ curves are in very good accord with the $\operatorname{CCSD}(\mathrm{T})$ ones, particularly for the intermediate and long-range interactions, while in the short-range regime small deviations are found. The largest difference is obtained for the $1-C_{2 v}$ and $3-\mathrm{C}_{2 v}$ orientations, where the $\mathrm{B} 3(\mathrm{H})$ predicts more stable structures by an energy of $0.6 \mathrm{kcal} / \mathrm{mol}$ compared to the corresponding $\operatorname{CCSD}(\mathrm{T})$ data. Also deeper well-depths are found for the $6-\mathrm{C}_{2 v}, 8-\mathrm{C}_{2 v}, 5-\mathrm{C}_{2 v}$, and 7- $\mathrm{C}_{2 v}$ conformers, whereas for the $9-\mathrm{C}_{s}$ and $10-\mathrm{C}_{3 v}$ the $\mathrm{B} 3(\mathrm{H})$ and $\operatorname{CCSD}(\mathrm{T})$ results are in excellent agreement. In general, for all points in Fig. 3 and for the energy range from -7 to $4 \mathrm{kcal} / \mathrm{mol} \mathrm{a}$ mean absolute error (MAE) of $0.16 \mathrm{kcal} / \mathrm{mol}$ is obtained between the $\mathrm{B} 3(\mathrm{H})$ interaction energies and the $\mathrm{CCSD}(\mathrm{T})$ ones. Compared now with the curves obtained from the recent analytical CCSD(T) parametrized PES by Xie et al. ${ }^{23}$ one can see significant differences in the intermediate and long-range regions for all configurations studied, and in particular for the 6- $\mathrm{C}_{2 v}, 8-\mathrm{C}_{2 v}, 9-\mathrm{C}_{s}$, and $10-\mathrm{C}_{3 v}$ ones, where these deviations are large even in the short-range area. As discussed previously by Prosmiti et al. ${ }^{19}$ the short-range forces for chemical binding are small, although considerable for the above mentioned structures, e.g., 9- $\mathrm{C}_{s}$ one, and also the relevant long-range interaction, mainly the charge-induced dipole and the charge-quadrupole terms, behaves differently depending on how $\mathrm{H}_{2}$ approaches a corner (cases 1, 3, and 

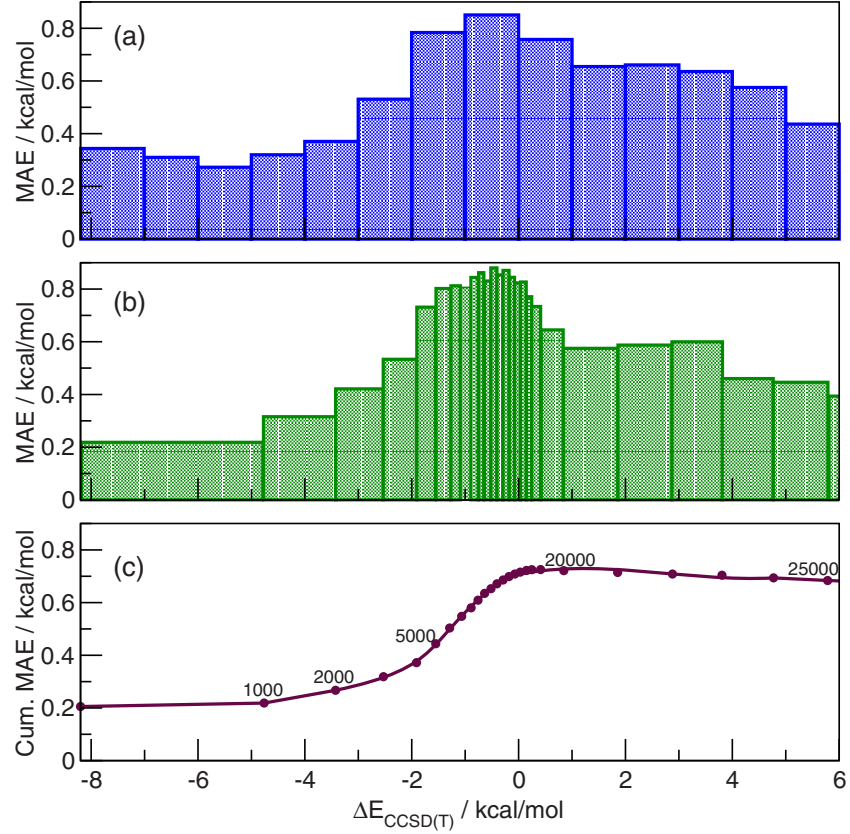

FIG. 4. Mean absolute error for the $\mathrm{B} 3(\mathrm{H})$ and $\mathrm{CCSD}(\mathrm{T})$ interaction energies as a function of the $\operatorname{CCSD}(\mathrm{T})$ ones obtained (a) for a fixed energy range of $1 \mathrm{kcal} / \mathrm{mol}$, (b) for a fixed number of 1000 data points, and (c) as a function of the number of points below each energy.

6 ), or a side $(5,7$, and 8$)$ or the center $(9$ and 10$)$ of the $\mathrm{H}_{3}^{+}$. We should note that the "artifact" for the intermediate to large intermolecular distances of the analytical PES seems that it may be attributed to the smoothness of the switching procedure adopted by Xie et $a .^{23}$ in order to represent correctly the long-range interactions.

In Fig. 4 we present the relation between the MAE in the interaction energies obtained from B3(H) and $\operatorname{CCSD}(\mathrm{T})$ calculations using the cc-pVQZ basis set as a function to the CCSD(T) interaction energy relative to the $\mathrm{H}_{3}^{+}+\mathrm{H}_{2}$ dissociation. We choose to calculate the $\mathrm{B} 3(\mathrm{H})$ and $\operatorname{CCSD}(\mathrm{T})$ energies at 30521 configurations of the $\mathrm{H}_{5}^{+}$to explore different energy regimes. As the distribution of the data points is not uniform with the energy, the mean absolute error values between the $\mathrm{B} 3(\mathrm{H})$ and $\mathrm{CCSD}(\mathrm{T})$ interaction energy values are estimated for both fixed energy range of $1 \mathrm{kcal} / \mathrm{mol}$ [see Fig. 4(a)] as well as for a fixed number of 1000 points [see Fig. 4(b)]. Also the cumulative mean absolute error value by increasing the number of data points is obtained and plotted [see Fig. 4(c)]. As we can see the MAE error is smaller at low energies, about $0.3 \mathrm{kcal} / \mathrm{mol}$, and increases up to 0.8 $\mathrm{kcal} / \mathrm{mol}$ for energies near the dissociation limit of $\mathrm{H}_{3}^{+}+\mathrm{H}_{2}$, where a higher number of data was available. The total MAE error for all negative energy points is $0.47 \mathrm{kcal} / \mathrm{mol}$, and for all positive energy ones $0.62 \mathrm{kcal} / \mathrm{mol}$, while a value of 0.54 $\mathrm{kcal} / \mathrm{mol}$ is obtained for the whole data set. As we have mentioned above, B3(H) calculations predict lower interaction energies than the $\operatorname{CCSD}(\mathrm{T})$ with somehow larger deviation from the $\operatorname{CCSD}(\mathrm{T})$ ones for the energies of dissociative configurations. However, we should mention that such approach provides a global, realistic, and computationally feasible representation of the $\mathrm{H}_{5}^{+}$surface.

Two-dimensional contour plots of the potential B3(H) DFT surface are shown in Fig. 5, where we choose different
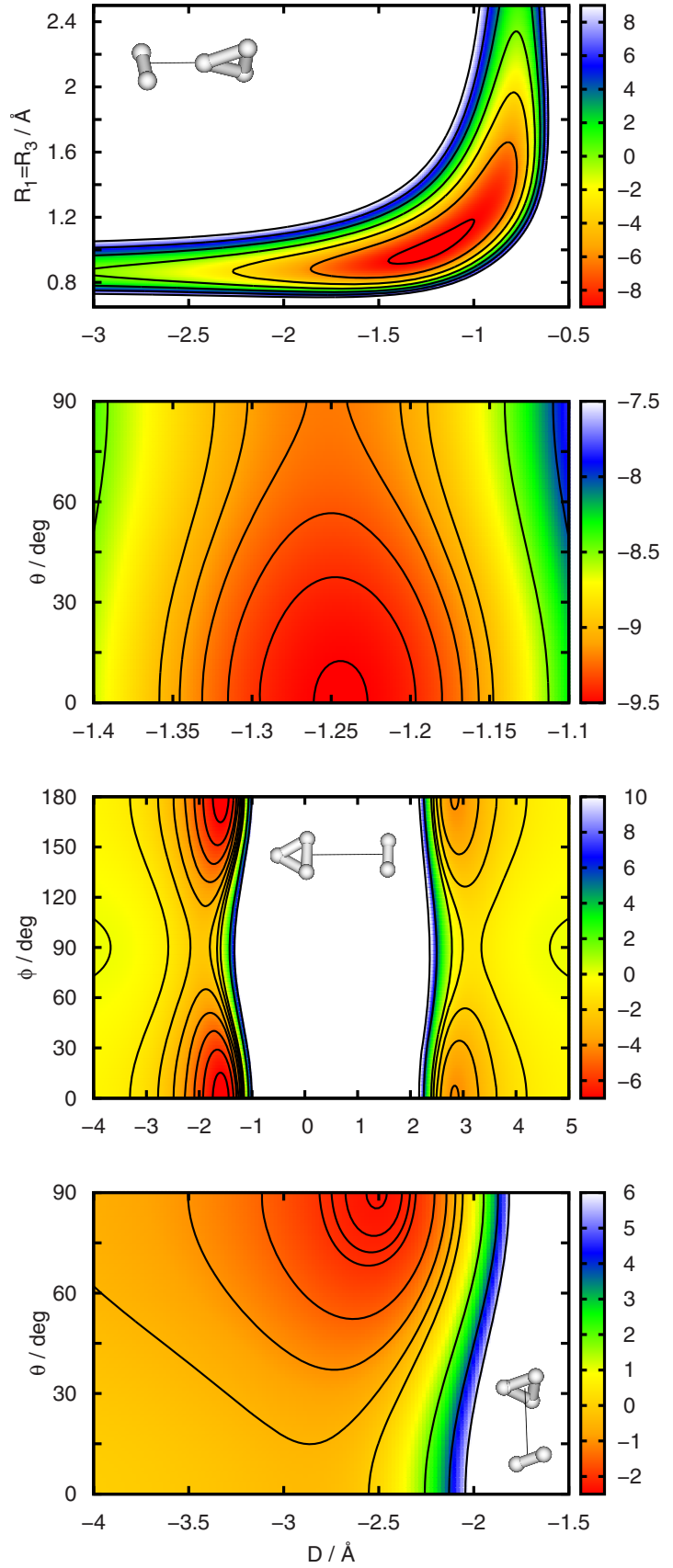

FIG. 5. Contour plots of the B3(H)/cc-pVQZ surface of the $\mathrm{H}_{5}^{+}$. In the inset of each panel the corresponding relative orientation for the $\mathrm{H}_{3}^{+}$and $\mathrm{H}_{2}$ monomers to $1-\mathrm{C}_{2 v}, 7-\mathrm{C}_{2 v}$, and $9-\mathrm{C}_{s}$ (from top to bottom panel) of $\mathrm{H}_{5}^{+}$is also shown. Contour lines are plotted for the energy ranges: -9.0 to $9.0 \mathrm{kcal} / \mathrm{mol}$ with an interval of $3.0 \mathrm{kcal} / \mathrm{mol}$ (top panel), -9.5 to $-9.0 \mathrm{kcal} / \mathrm{mol}$ and -9.0 to $8.0 \mathrm{kcal} / \mathrm{mol}$ with intervals of 0.1 and $0.5 \mathrm{kcal} / \mathrm{mol}$, respectively (first middle panel), -7.0 to $0.0 \mathrm{kcal} / \mathrm{mol}$ and $0.0-10.0 \mathrm{kcal} / \mathrm{mol}$ with intervals of 1.0 and $5.0 \mathrm{kcal} / \mathrm{mol}$, respectively (second middle panel), -7.0 to 0.0 $\mathrm{kcal} / \mathrm{mol}$ and $0.0-10.0 \mathrm{kcal} / \mathrm{mol}$ with steps of 0.1 and $5 \mathrm{kcal} / \mathrm{mol}$, respectively (bottom panel).

orientations of the $\mathrm{H}_{5}^{+}$to provide an overall picture of the interaction. The representation of the PES is displayed in four plots. They show projections of the interaction energy for three different fixed configurations of $\mathrm{H}_{5}^{+}$, corresponding to $1-\mathrm{C}_{2 v}$ (see top and first middle panels of Fig. 5), 7- $\mathrm{C}_{2 v}$ (see second middle panel of Fig. 5), and 9- $\mathrm{C}_{s}$ (see bottom panel of Fig. 5) ones. These configurations are also indicated in the inset of Fig. 5. One $\mathrm{H}$ atom of the $\mathrm{H}_{3}^{+}$is positioned at 
the origin of the coordinate system, and its three $\mathrm{H}$ atoms are placed in the XY-plane. $R^{\prime}, \theta$, and $\phi$ are the spherical coordinates of the center of mass of $\mathrm{H}_{2}$ with respect to the fixed origin, while $\mathrm{D}$ and $R_{1} / R_{2} / R_{3}$ are the intermolecular distance between the fixed $\mathrm{H}$ atom and the center of mass of $\mathrm{H}_{2}$, and the $\mathrm{HH}$ bond lengths in the $\mathrm{H}_{3}^{+}$, as they were defined above (see Table I). In the top and first middle panels the equipotential curves are shown in the (D, $\left.R_{1}\right)$ with $R_{1}=R_{3}$ and (D, $\theta$ ) coordinates, respectively, with $\mathrm{H}_{5}^{+}$fixed at $1-\mathrm{C}_{2 v}$ orientation. The contours of the surface are demonstrated around the global minimum, as well as the area nearby the planar $3-\mathrm{C}_{2 v}$ saddle-point between the two symmetric no-planar $1-\mathrm{C}_{2 v}$ conformers. One can see the flatness of the potential around the minimum, as well as the dissociation channels to $\mathrm{H}_{3}^{+}$ $+\mathrm{H}_{2}$ in $\mathrm{D}$ and $R_{1}=R_{3}$ coordinates. In the second middle panel contour lines are plotted in the $(\mathrm{D}, \phi)$ plane with the $\mathrm{H}_{5}$ fixed in $7-\mathrm{C}_{2 v}$ geometry. The details of the surface around the $3-\mathrm{C}_{2 v}$ and $6-\mathrm{C}_{2 v}$ as well as for the $7-\mathrm{C}_{2 v}$ and $8-\mathrm{C}_{2 v}$ stationary points are shown. As we mentioned above $3-\mathrm{C}_{2 v}$ is first-order saddle-point, while $6-\mathrm{C}_{2 v}$ and $7-\mathrm{C}_{2 v}$ are second order ones, and $8-\mathrm{C}_{2 v}$ a third order one. In turn, in the bottom panel of Fig. 5 the PES around the 9- $\mathrm{C}_{s}$ geometry (third order saddle-point) is presented together with the nearby $10-\mathrm{C}_{3 v}$ (fourth order saddle-point) one. As one can expect these differences in the order of the saddle-points appear in the plots.

In the following we will discuss the stability of $\mathrm{H}_{5}^{+}$by determining its dissociation energy, as well as the enthalpy variation for the $\mathrm{H}_{5}^{+} \rightarrow \mathrm{H}_{3}^{+}+\mathrm{H}_{2}$ given by

$$
\Delta H=\left[H_{\left(\mathrm{H}_{3}^{+}\right)}+H_{\mathrm{H}_{2}}\right]-H_{\mathrm{H}_{5}^{+}}
$$

or

$$
\Delta H=-D_{e}+\Delta(\mathrm{ZPVE})+\Delta(\epsilon(T)),
$$

where $H$ are the enthalpies for $\mathrm{H}_{2}, \mathrm{H}_{3}^{+}$, and $\mathrm{H}_{5}^{+}$given by $\mathrm{H}^{298.15}=E+\mathrm{ZPVE}+\epsilon(T), \quad D_{e}=E\left(\mathrm{H}_{5}^{+}\right)-\left[E\left(\mathrm{H}_{3}+\right)+E\left(\mathrm{H}_{2}\right)\right]$ $+E_{\mathrm{BSSE}}$, ZPVE are the zero-point vibrational energy corrections, and $\epsilon(T)$ are the thermal corrections, accounting the effects of molecular translation, vibration, and rotation at specific temperature and pressure ${ }^{67}$ for $\mathrm{H}_{2}, \mathrm{H}_{3}^{+}$, and $\mathrm{H}_{5}^{+}$obtained from the optimization $\mathrm{B} 3(\mathrm{H}) / \mathrm{cc}-\mathrm{pVQZ}$ calculations.

By considering the results of the harmonic vibrational frequency analysis, zero-point vibrational energy, as well as thermal corrections for both reactants and products, the dissociation energies including $\mathrm{ZPVE}, \mathrm{D}_{0}$, and enthalpy variation $-\Delta H$ for the equilibria clustering $\mathrm{H}_{3}^{+}+\mathrm{H}_{2} \rightleftharpoons \mathrm{H}_{5}^{+}$reaction were obtained. In Table $\mathrm{V}$ we present the calculated values of the present study and compared them with the ones from previous theoretical calculations, ${ }^{14-16,18,20,21,23,27}$ as well as various experimental measurements. ${ }^{28-31,33,37-39}$ As we can see in Table $\mathrm{V}$ the predicted $\mathrm{D}_{e}$ and $\mathrm{D}_{0}$ energies computed here by the DFT calculations are varied from 13.30 and $11.03 \mathrm{kcal} / \mathrm{mol}$ using the BLYP to 9.47 and $6.79 \mathrm{kcal} / \mathrm{mol}$ with the $\mathrm{B} 3(\mathrm{H})$ functional, respectively. The results obtained by $\mathrm{B} 3(\mathrm{H})$ are in fairly good agreement with those obtained by $\mathrm{CC}$ studies. ${ }^{18,20}$ Whereas the $\mathrm{B} 3(\mathrm{H})$ values are somewhat higher by $0.8-0.9 \mathrm{kcal} / \mathrm{mol}$, compared with the ones obtained by previous CC-R12 and CCSD(T) studies, ${ }^{18,20}$ the deviations become 3.6, 4.2 , and $4.7 \mathrm{kcal} / \mathrm{mol}$, respectively, for

TABLE V. Theoretical dissociation energies $\mathrm{D}_{e}$ and $\mathrm{D}_{0}$ (in $\mathrm{kcal} / \mathrm{mol}$ ) for $\mathrm{H}_{5}^{+}$, together with enthalpy variations obtained in the present DFT calculations, as well as in previous studies and compared with experimental values of

\begin{tabular}{|c|c|c|c|c|}
\hline Theory or Expt. & $\mathrm{D}_{e}$ & $\Delta(\mathrm{ZPVE})$ & $\mathrm{D}_{0}$ & $\Delta H(153 / 298.15 \mathrm{~K})$ \\
\hline BLYP/cc-pVQZ & 13.30 & 2.27 & 11.03 & $11.41 / 11.70$ \\
\hline B3PW91/cc-pVQZ & 12.80 & 2.53 & 10.27 & $10.91 / 11.20$ \\
\hline B3LYP/cc-pVQZ & 12.23 & 2.22 & 10.01 & $10.40 / 10.69$ \\
\hline $\mathrm{B} 3(\mathrm{H}) / \mathrm{cc}-\mathrm{pVQZ}\left(1 \mathrm{C}_{2 v}\right)$ & 9.47 & 2.68 & 6.79 & $7.64 / 7.93$ \\
\hline $\mathrm{B} 3(\mathrm{H}) / \mathrm{cc}-\mathrm{pVQZ}\left(2 \mathrm{D}_{2 d}\right)$ & 9.38 & & 6.70 & $7.55 / 7.84$ \\
\hline $\mathrm{DFT}^{\mathrm{a}}$ & & & 14.5 & \\
\hline $\mathrm{G} 2(\mathrm{MP} 2)^{\mathrm{b}}$ & 8.90 & & & $6.20 / \cdots$ \\
\hline $\mathrm{MP} 4^{\mathrm{c}}$ & 7.84 & & & $6.91 / \cdots$ \\
\hline $\mathrm{CC}-\mathrm{R} 12^{\mathrm{d}}$ & 8.58 & 2.48 & 6.09 & \\
\hline $\operatorname{CCSD}(T)^{\mathrm{e}}$ & 8.65 & 2.74 & 5.91 & $7.10 / 7.39$ \\
\hline$M P 2^{f}$ & 7.70 & $\cdots$ & 5.00 & \\
\hline CC-PES ${ }^{\mathrm{g}}$ & 8.30 & 2.73 & 5.57 & \\
\hline CC-PES/DMC & 8.30 & $\cdots$ & 6.37 & \\
\hline Ref. 37 & & & & $5.1 \pm 1.2$ \\
\hline Ref. 28 & & & & 9.7 \\
\hline Ref. 29 & & & & 9.6 \\
\hline Ref. 38 & & & & $8.1 \pm 0.1$ \\
\hline Ref. 39 & & & & $5.8 \pm 1.2$ \\
\hline Ref. 30 & & & & $6.6 \pm 0.3$ \\
\hline Ref. 31 & & & & $6.9 \pm 0.3$ \\
\hline Ref. 33 & & & & $7.0 \pm 0.1$ \\
\hline Ref. 35 & & & $<7.44$ & \\
\hline
\end{tabular}
dissociation enthalpies for $\mathrm{H}_{5}^{+} \rightarrow \mathrm{H}_{3}^{+}+\mathrm{H}_{2}$.

${ }^{\mathrm{a}}$ Reference 14.

${ }^{\mathrm{b}}$ Reference 15 .

${ }^{\mathrm{c}}$ Reference 16.

${ }^{\mathrm{d}}$ Reference 18.

${ }^{\mathrm{e}}$ Reference 20.
${ }^{\mathrm{f}}$ Reference 21.
${ }^{\mathrm{g}}$ Reference 23.
${ }^{\mathrm{h}}$ Reference 27.

B3LYP, B3PW91, and BLYP functionals. These DFT calculations predict a stronger bound $\mathrm{H}_{5}^{+}$complex than the $\mathrm{CC}$ ones, and as we have mentioned above only one, the $2-\mathrm{D}_{2 d}$, a very flat potential well. In contrast, we should note that the MP2 calculations ${ }^{21}$ underestimate the binding energies by $0.9 \mathrm{kcal} / \mathrm{mol}$, that is the same factor with the $\mathrm{B} 3(\mathrm{H})$ ones compared to the CC data. Also we present a comparison with the latest data for the $\mathrm{D}_{0}$ value predicted by diffusion Monte Carlo calculations employing the surface by Xie et $a .^{23} \mathrm{In}$ this latter study by including correctly the anharmonicities of the surface, a $\mathrm{D}_{0}$ value of $6.37 \mathrm{kcal} / \mathrm{mol}$ has been predicted; however, the zero-point averaged structure of $\mathrm{H}_{5}^{+}$has been found to be of the $\mathrm{D}_{2 d}$ geometry. ${ }^{27}$ Given that the energy difference between the $1-\mathrm{C}_{2 v}$ and $2-\mathrm{D}_{2 d}$ is only $0.09 \mathrm{kcal} / \mathrm{mol}$ at $\mathrm{B} 3(\mathrm{H})$ calculations, we also list in Table $\mathrm{V}$ a $\mathrm{D}_{0}$ value within the harmonic approximation for the $2-\mathrm{D}_{2 d}$ configuration of $6.70 \mathrm{kcal} / \mathrm{mol}$. The only experimental data available on the $\mathrm{D}_{0}$ energy for the $\mathrm{H}_{5}^{+}$have been reported recently by Cheng et al. ${ }^{35}$ The authors based on the lower-energy band at $2603 \mathrm{~cm}^{-1}$ in the recorded IR spectrum of $\mathrm{H}_{5}^{+}$have established a firm upper limit corresponding to $7.44 \mathrm{kcal} / \mathrm{mol}$. This value is consistent, and very close to the one predicted by the harmonic $\mathrm{B} 3(\mathrm{H})$ estimate, although is slightly higher than all theoretical predicted ones (see Table V).

Further, in order to compare with more experimental data the computed enthalpy variation values $-\Delta H$ are listed in the last column of Table V. Several experimental data are available for the clustering reaction over the range of tem- 
perature of 25-300 K..$^{28-31,33,37-39}$ The enthalpy variation values are temperature dependent, and generally increase as temperature increases. Therefore, for a direct comparison with the most recent experimental data (see van't Hoff plots in Refs. 30, 31, and 33), $-\Delta H$ values are given for $298.15 \mathrm{~K}$, and also for comparison with previous calculations, for 153 $\mathrm{K}$. Once again the BLYP, B3PW91, and B3LYP calculations provide enthalpy values in poor agreement with the experimental data. These DFT values are high enough compared to experimental data with deviations of $67 \%-48 \%$. Such significant differences emphasize the inaccuracy of the corresponding DFT calculations. On the other hand the $\mathrm{B} 3(\mathrm{H})$ results predict an enthalpy variation value of 7.93 and 7.64 $\mathrm{kcal} / \mathrm{mol}$ at 298.15 and $153 \mathrm{~K}$, respectively, that is consistent with the MP2, MP4, and CCSD(T) ones. By comparing these values with the experimental ones, ${ }^{30,31,33}$ we found a deviation of $10 \%$, suggesting that $\mathrm{B} 3(\mathrm{H})$ calculations can quantitatively describe the $\mathrm{H}_{5}^{+}$system.

\section{SUMMARY AND CONCLUSIONS}

We presented a potential energy surface by performing DFT calculations at a large number of geometries for the $\mathrm{H}_{5}^{+}$ cluster. Different GGA and hybrid functionals were used and their efficiency to treat the energetics of the weak bonds that are present in the $\mathrm{H}_{5}^{+}$cluster was checked. In this way equilibrium structures as well as the features of intermolecular interaction at intermediate and long distances were investigated. Among all functionals studied, a hybrid one, namely, $\mathrm{B} 3(\mathrm{H})$, which has been specially designed for the description of hydrogen-only systems, was found to be able to recover with remarkable accuracy the main features on the $\mathrm{H}_{5}^{+}$surface. Our results were compared with the most accurate to date analytical $\operatorname{CCSD}(\mathrm{T})$ potential surface, previous high level CC-R12 and CCSD(T) calculations, as well as with $\operatorname{CCSD}(\mathrm{T})$ additional reference computations carried out here for this purpose. We found that with this functional the calculated surface has the appropriate topology to describe with very good accuracy and low computational cost all aspects of the interaction $\mathrm{H}_{5}^{+}$potential, such as the known ten lower stationary points, including the transition state for the proton transfer between the two $\mathrm{H}_{2}$ molecules, as well as the correct asymptotic behavior of the long-range electrostatic interactions for all configurations studied. Such description is important for studying the role of this ion-molecule complex in the mechanisms of collision or fragmentation reactions, with a particular interest at low temperatures due to its relevance in astrophysical applications.

Further, total interaction energies and normal frequencies for these conformers were obtained and show a good accord with benchmark results. A more quantitative insight into bonding was obtained from the comparison of the theoretical values of dissociation energies and measured dissociation enthalpies. The dissociation energies and enthalpy variations for the equilibrium $\mathrm{H}_{3}^{+}+\mathrm{H}_{2} \rightleftharpoons \mathrm{H}_{5}^{+}$reaction were estimated for the B3(H)/cc-pVQZ calculations and compared with previous theoretical predictions, as well as with various, earlier and recent, experimental data available. In general the values obtained from the B3(H)/cc-pVQZ computations pre- dict a more tighter $\mathrm{C}_{2 v}$ structure for the $\mathrm{H}_{5}^{+}$, and compare very well with benchmark $\operatorname{CCSD}(\mathrm{T})$ results. The present B3(H) DFT data are also found in a very good quantitative agreement with the most recent experimental data.

Even though significant progress has been recently made on the potential surface calculation of $\mathrm{H}_{5}^{+}$we think that there is still room for further improvement. In one hand, the accuracy of the present DFT approach in representing the $\mathrm{H}_{5}^{+}$ surface was confirmed by more extensive comparisons with high level $\operatorname{CCSD}(\mathrm{T})$ calculations. Based on these data we report a total MAE value of $0.5 \mathrm{kcal} / \mathrm{mol}$ for energies up to 6 $\mathrm{kcal} / \mathrm{mol}$ for the whole set of data, with slightly larger deviations especially in regions corresponding to dissociative configurations. On the other hand, comparison with previous analytical CCSD(T) surface shows that improvements are needed in the functional form for the asymptotic regions, ${ }^{68}$ and a global parametrized analytical potential for $\mathrm{H}_{5}^{+}$still remains a challenge. Therefore, studies in both directions, such as traditional analytical fitting procedures, ${ }^{68}$ as well as improved parametrized DFT functionals, are necessary if progress is to be made on the open questions on the $\mathrm{H}_{5}^{+}$ dynamics.

Further, this work underlines the interest in determining accurate potential energy surfaces within the DFT framework for the protonated hydrogen clusters. In case of $\mathrm{H}_{5}^{+}$we show that such approach yields a reliable interaction potential, and thus first-principles dynamics calculations can be carried out to study the spectroscopy, collision, and/or fragmentation dynamics of the system. ${ }^{69}$ In fact, the $\mathrm{H}_{5}^{+}$can be regarded as the simplest system including internal proton transfer, and therefore the investigation of its molecular properties is an important step to understand larger complexes. Accordingly, one expects that reasonable description of energetics, low-lying structures, and dissociation asymptotes will be possible using such functional for larger $\mathrm{H}_{n}^{+}$clusters. It would be interesting to see if larger sizes of these clusters confirm this picture. Work in these directions is in progress.

\section{ACKNOWLEDGMENTS}

The authors thank Centro de Calculo (IFF), CTI (CSIC), and CESGA for allocation of computer time. This work has been supported by CSIC (Grant No. PIE-2008501085), DGICYT, Spain (Grant Nos. FIS2007-62002, CTQ2007-62898, and CTQ2007-63332), and MICINN: Consolider (Grant No. CSD2009-00038).

\footnotetext{
${ }^{1}$ V. G. Anicich, Astrophys. J., Suppl. Ser. 84, 215 (1993).

${ }^{2}$ D. Gerlich, E. Herbst, and E. Roueff, Planet. Space Sci. 50, 1275 (2002).

${ }^{3}$ J. T. Hallett, D. E. Shemansky, and X. Liu, Astrophys. J. 624, 448 (2005).

${ }^{4}$ T. Ditmire, J. Zweiback, V. P. Yanovsky, T. E. Cowan, G. Hays, and K. B. Wharton, Nature (London) 398, 489 (1999).

${ }^{5}$ J. Zweiback, R. A. Smith, T. E. Cowan, G. Hays, K. B. Wharton, V. P. Yanovsky, and T. Ditmire, Phys. Rev. Lett. 84, 2634 (2000).

${ }^{6}$ M. Isla and J. A. Alonso, Phys. Rev. A 72, 023201 (2005); J. Chem. Phys. C 111, 17765 (2007).

${ }^{7}$ P. Chen, X. Wu, J. Lin, and K. L. Tan, Science 285, 91 (1999).

${ }^{8}$ W.-Q. Deng, X. Xu, and W. A. Goddard, Phys. Rev. Lett. 92, 166103 (2004).

${ }^{9}$ R. Ahlrichs, Theor. Chem. Acc. 39, 149 (1975).

${ }^{10}$ Y. Yamaguchi, J. F. Gaw, B. Remington, and H. F. Shaefer III, J. Chem. Phys. 86, 5072 (1987).
} 
${ }^{11}$ U. Nagashima, K. Morokuma, and H. Tanaka, J. Phys. Chem. 96, 4294 (1992).

${ }^{12}$ M. Farizon, H. Chermette, and B. Farizon-Mazuy, J. Chem. Phys. 96, 1325 (1992)

${ }^{13}$ T. Pang, Chem. Phys. Lett. 228, 555 (1994).

${ }^{14}$ I. Štich, D. Marx, M. Parrinello, and K. Terakura, J. Chem. Phys. 107, 9482 (1997)

${ }^{15}$ E. W. Ignacio and S. Yamabe, Chem. Phys. Lett. 287, 563 (1998).

${ }^{16}$ M. Barbatti, G. Jalbert, and M. A. C. Nascimento, J. Chem. Phys. 113, 4230 (2000)

${ }^{17}$ W. P. Kraemer, V. Spirko, and O. Bludský, J. Mol. Spectrosc. 164, 500 (1994).

${ }^{18}$ H. Müller and W. Kutzelnigg, Phys. Chem. Chem. Phys. 2, 2061 (2000).

${ }^{19}$ R. Prosmiti, A. A. Buchachenko, P. Villarreal, and G. Delgado-Barrio, Theor. Chem. Acc. 106, 426 (2001).

${ }^{20}$ R. Prosmiti, P. Villarreal, and G. Delgado-Barrio, J. Phys. Chem. A 107, 4768 (2003)

${ }^{21}$ G. E. Moyano and M. A. Collins, J. Chem. Phys. 119, 5510 (2003).

${ }^{22}$ Y. Ohta, J. Ohta, and K. Kinugawa, J. Chem. Phys. 121, 10991 (2004).

${ }^{23}$ Z. Xie, B. J. Braams, and J. M. Bowman, J. Chem. Phys. 122, 224307 (2005).

${ }^{24}$ V. Špirko, T. Amano, and W. P. Kraemer, J. Chem. Phys. 124, 244303 (2006).

${ }^{25}$ K. Park and J. C. Light, J. Chem. Phys. 126, 044305 (2007).

${ }^{26}$ G. M. e Silva, R. Gargano, W. B. da Silva, L. F. Roncaratti, and P. H. Acioli, Int. J. Quantum Chem. 108, 2318 (2008).

${ }^{27}$ P. H. Acioli, Z. Xie, B. J. Braams, and J. M. Bowman, J. Chem. Phys 128, 104318 (2008)

${ }^{28}$ S. L. Bennett and F. H. Field, J. Am. Chem. Soc. 94, 8669 (1972).

${ }^{29}$ K. Hiraoka and P. Kebarle, J. Chem. Phys. 62, 2267 (1975).

${ }^{30}$ R. J. Beuhler, S. Ehrenson, and L. Friedman, J. Chem. Phys. 79, 5982 (1983).

${ }^{31}$ K. Hiraoka, J. Chem. Phys. 87, 4048 (1987).

${ }^{32}$ M. Okumura, L. I. Yeh, and Y. T. Lee, J. Chem. Phys. 88, 79 (1988).

${ }^{33}$ K. Hiraoka and T. Mori, J. Chem. Phys. 91, 4821 (1989).

${ }^{34}$ Y. K. Bae, Chem. Phys. Lett. 180, 179 (1991).

${ }^{35}$ T. C. Cheng, B. Bandyopadyay, Y. Wang, S. Carter, B. J. Braams, J. M. Bowman, and M. A. Duncan, J. Phys. Chem. Lett. 1, 758 (2010).

${ }^{36}$ O. Kornilov and J. P. Toennies, J. Chem. Phys. 128, 194306 (2008).

${ }^{37}$ U. A. Arifov, S. L. Pozharov, I. G. Chernov, and Z. A. Mukhamediev, High Energy Chem. 5, 69 (1971).

${ }^{38}$ R. Johnsen, C. Huang, and M. A. Biondi, J. Chem. Phys. 65, 1539 (1976).

${ }^{39}$ M. T. Elford, J. Chem. Phys. 79, 5951 (1983).

${ }^{40}$ K. Giles, N. G. Adams, and D. Smith, J. Phys. Chem. 96, 7645 (1992).

${ }^{41}$ M. Cordonnier, D. Uy, R. M. Dickson, K. E. Kerr, Y. Zhang, and T. Oka, J. Chem. Phys. 113, 3181 (2000).

${ }^{42}$ H. Roberts, E. Herbst, and T. J. Millar, Mon. Not. R. Astron. Soc. 336,
283 (2002).

${ }^{43}$ E. Hugo, O. Asvany, and S. Schlemmer, J. Chem. Phys. 130, 164302 (2009).

${ }^{44}$ D. Gerlich, F. Windisch, P. Hlavenka, R. Plašil, and J. Glosik, Philos. Trans. R. Soc. London, Ser. A 364, 3007 (2006).

${ }^{45}$ M. J. T. Jordan, K. C. Thompson, and M. A. Collins, J. Chem. Phys. 102, 5647 (1995)

${ }^{46}$ T.-S. Ho and H. Rabitz, J. Chem. Phys. 119, 6433 (2003).

${ }^{47}$ L. M. Raff, M. Malshe, M. Hagan, D. I. Doughan, M. G. Rockley, and R. Komanduri, J. Chem. Phys. 122, 084104 (2005).

${ }^{48}$ R. Dawes, D. L. Thompson, Y. Guo, A. F. Wagner, and M. Minkoff, J. Chem. Phys. 126, 184108 (2007).

${ }^{49}$ M. Barbatti, G. Jalbert, and M. A. C. Nascimento, J. Chem. Phys. 114, 7066 (2001).

${ }^{50}$ M. Barbatti and M. A. C. Nascimento, J. Chem. Phys. 119, 5444 (2003).

${ }^{51}$ W. L. Hase, K. Song, and M. Gordon, Comput. Sci. Eng. 5, 36 (2003).

${ }^{52}$ R. Car and M. Parrinello, Phys. Rev. Lett. 55, 2471 (1985).

${ }^{53}$ H. Jiao, P. von R. Schleyer, and M. N. Glukhovtsev, J. Phys. Chem. 100, 12299 (1996).

${ }^{54}$ P. Bokes, I. Štich, and L. Mitas, Int. J. Quantum Chem. 83, 86 (2001).

${ }^{55}$ P. Barragán, R. Prosmiti, P. Villarreal, and G. Delgado-Barrio, "Global potential energy surface for the ground electronic state of $\mathrm{H}_{3}^{+}$: A DFT approach," Int. J. Quantum Chem. (2010) (in press).

${ }^{56}$ A. D. Becke, J. Chem. Phys. 98, 5648 (1993).

${ }^{57}$ H. Chermette, H. Razafinjanahary, and L. Carrion, J. Chem. Phys. 107, 10643 (1997).

${ }^{58}$ M. J. Frisch, G. W. Trucks, H. B. Schlegel et al., GAUSSIAN 03, Revision C.02, Gaussian, Inc., Wallingford, CT, 2004.

${ }^{59}$ See http://www.cpmd.org/cpmd.html.

${ }^{60}$ A. D. Becke, Phys. Rev. A 38, 3098 (1988); C. Lee, W. Yang, and R. G. Parr, Phys. Rev. B 37, 785 (1988); J. P. Perdew, K. Burke, and M. Ernzerhof, Phys. Rev. Lett. 77, 3865 (1996).

${ }^{61}$ J. P. Perdew and Y. Wang, Phys. Rev. B 45, 13244 (1992).

${ }^{62}$ N. C. Handy and A. J. Cohen, Mol. Phys. 99, 403 (2001).

${ }^{63}$ D. Vanderbilt, Phys. Rev. B 41, 7892 (1990); K. Laasonen, R. Car, C. Lee, and D. Vanderbilt, ibid. 43, 6796 (1991).

${ }^{64} \mathrm{U}$. von Barth and R. Car (unpublished).

${ }^{65}$ K. A. Peterson, D. E. Woon, and T. H. Dunning, Jr., J. Chem. Phys. 100, 7410 (1994).

${ }^{66}$ C. Schwartz, Phys. Rev. 126, 1015 (1962)

${ }^{67}$ D. A. McQuarrie and J. D. Simon, Molecular Thermodynamics (University Science Books, Sausalito, 1999).

${ }^{68}$ A. Aguado, P. Barragán, R. Prosmiti, G. Delgado-Barrio, P. Villarreal, and O. Roncero, J. Chem. Phys. 133, 024306 (2010).

${ }^{69}$ R. Pérez de Tudela, P. Barragán, R. Prosmiti, P. Villarreal, and G. Delgado-Barrio, "Internal proton transfer and $\mathrm{H}_{2}$ rotations in the $\mathrm{H}_{5}^{+}$cluster: A marked influence on its thermal equilibrium state," J. Chem. Phys. (2010) (submitted). 